\title{
A FORMAÇÃO DOCENTE A PARTIR DO ESTÁGIO SUPERVISIONADO II E AS OCUPAÇÕES DOS ESTUDANTES SECUNDARISTAS
}

\author{
Nathalia Ohana Ferreira Santos \\ Universidade Federal de Uberlândia; Graduanda em Geografia; \\ nathaliaohana16@gmail.com
}

\section{Introdução}

O curso de graduação em Geografia da Universidade Federal de Uberlândia (UFU) por meio da disciplina obrigatória "Estágio Supervisionado" do I ao IV dividido em quatro semestres, possibilita aos seus graduandos o contato direto com o "mundo educacional" de modo a fomentar o desenvolvimento e aperfeiçoamento da prática pedagógica.

Nesse sentido, torna-se possível a tais graduandos se capacitarem através do apoio e orientação do professor regente da disciplina. A esses, existe a possibilidade de estudar os quatro semestres com o mesmo professor. Por conseguinte, uma maior aproximação na relação graduando-professor orientador é construída, favorecendo o diálogo e uma boa relação entre ambas as partes de modo a legitimar a formação docente.

A importância do Estágio Supervisionado se dá por possibilitar a nós, graduandos, um expressivo contato com a nossa futura profissão. A vivência nas escolas é primordial para que conheçamos a realidade do sistema de ensino do nosso país. Desse modo, após a concretização da graduação, nos tornaremos profissionais que sejam capazes de atender as necessidades do processo educacional.

Situações como a falta de professores, de material didático, de salas de aula com estrutura adequada e até mesmo de lanche para os alunos são condições desfavoráveis ao ensino-aprendizagem que comparecem em diversas escolas e afetam diretamente diversos alunos, sobretudo aqueles que se encontram em uma situação de vulnerabilidade socioeconômica. O processo de graduação enfatiza a nossa formação enquanto futuros professores e, somente através da realização do estágio que ficamos a par dessas condições que fomentam a precarização da escola e do ensino.

A precarização da educação pública que vêm ocorrendo no Brasil ao longo dos últimos anos demonstra a despreocupação dos nossos governantes diante da educação pública. E, a Universidade por si, não consegue suprir tamanhas necessidades através da 
formação docente. $\mathrm{O}$ professor é apenas é um dos componentes essenciais para o funcionamento adequado e de qualidade da escola.

A negação da importância de um ensino público e de qualidade tanto para os alunos quanto para os profissionais envolvidos vem se materializando, sobretudo nos três últimos anos, através das reformas promovidas pelo atual Governo.

\section{O nascimento das ocupações}

O processo de impeachment ${ }^{l}$ contra a presidenta eleita Dilma Rousseff e posterior golpe parlamentar ocorrido em nosso país desencadearam uma série de complicações que vão transformar o futuro de todos os brasileiros.

A proposta de lei "Escola sem partido", a Proposta de Emenda à Constituição PEC 55 antiga PEC 241 e a "Reforma do Ensino médio" foram causa principal para a eclosão de greves no país.

A "Reforma do Ensino Médio" foi sancionada pelo Presidente Michel Temer no mês de fevereiro de 2017. Foi elaborada pelo Ministério da Educação e defendida pelo Ministro da Educação Mendonça Filho. A Reforma refere-se a um conjunto de novas diretrizes a serem aplicadas no ensino médio.

Uma das principais mudanças que a Reforma trás e que afeta diretamente o ensino, é a possibilidade de flexibilização do currículo, além da inserção do ensino técnico e a consolidação das escolas em tempo integral. Além disso, a principal mudança que afetará o processo do ensino-aprendizagem, é a retirada do currículo da obrigatoriedade das disciplinas de Artes, Educação Física, Filosofia e Sociologia e, a autorização para que profissionais com "notório saber" reconhecidos pelo sistema de ensino, possam dar aulas na formação técnica.

Entre os vários problemas apresentados durante a tramitação da Reforma, a negação da realização de um debate aberto com a sociedade e os profissionais diretamente afetados por tal medida foi propulsor para inúmeros protestos realizados em vários lugares do Brasil.

Em matéria publicada pelo G1 (Outubro/2016):

Estudantes, professores e trabalhadores administrativos da Universidade Federal de Uberlândia (UFU) iniciaram nesta segunda-feira (24) uma greve por tempo indeterminado. Na Escola de Educação Básica (Eseba) o 
movimento foi aderido parcialmente. A greve foi decidida após assembléias realizadas pela Associação dos Docentes da UFU (Adufu), Sindicato dos Trabalhadores Técnico-Administrativos em Instituições Federais de Ensino Superior de Uberlândia (Sintet) e o Diretório Central dos Estudantes (DCE). Conforme informações da presidente da Adufu, Jojetania da Silva Ferreira, o principal motivo do movimento é a tramitação da Proposta de Emenda Constitucional (PEC) 241, que prevê mudanças na educação do país. Ela disse ao G1 que ainda há um balanço do percentual de pessoas paralisadas, mas adiantou que o movimento envolve os três seguimentos e que portanto, a adesão é forte.

Nesse sentido, a Universidade Federal de Uberlândia entrou em greve junto com outras Universidades do país para lutar por nossos direitos. Servidores públicos, estudantes secundaristas e universitários se uniram para lutar bravamente contra as atrocidades cometidas pelos governantes do nosso país. Universidades, Escolas Estaduais e Federais por todo o país foram ocupadas.

Devido ao fato de que a Universidade deliberou greve, a melhor escolha tomada durante a realização do Estágio Supervisionado II foi entrar no movimento de greve e participar das atividades que foram promovidas nesse período. Em acordo com o professor orientador, paramos as atividades previstas no estágio II para a Escola Estadual Segismundo Pereira para lutar. Algum tempo depois a escola em que estava realizando o estágio também entrou em greve e foi ocupada por estudantes. $\mathrm{O}$ movimento dos estudantes secundaristas ocorreu em todo o território nacional.

Em matéria publicada pelo Rede Brasil Atual (Outubro/2016),

A União Nacional dos Estudantes (UNE) divulgou hoje (25) novo balanço de universidades ocupadas no país. São 82 no total, além de 1.108 escolas secundaristas ocupadas, segundo boletim divulgado nesta terça-feira, às $18 \mathrm{~h} 44$ pela União Brasileira dos Estudantes (Ubes). Os estudantes protestam contra a aprovação da Proposta de Emenda à Constituição (PEC) 241, que prevê um teto para gastos públicos em áreas como saúde e educação para os próximos 20 anos ao limite da inflação do ano anterior. [...] 'Existe um movimento de greve geral (professores, técnicos e estudantes) já em várias universidades, greve estudantil e ocupação de reitorias que só cresce. Os estudantes são terminantemente contra o congelamento de investimentos que vão sucatear ainda mais as universidades e vamos paralisar o Brasil para defender a educação pública', afirmou em nota o diretor de Comunicação da União Nacional dos Estudantes (UNE), Mateus Weber. 
O movimento de greve resistiu até o último minuto, onde milhares de estudantes, professores, servidores públicos e comunidade foram até Brasília-DF protestar no dia da última votação da PEC 55. Mesmo lutando, demonstrando o quanto não estávamos de acordo com a medida, o povo foi duramente repreendido e atacado pela cavalaria, e pela tropa de choque do Exército. A PEC foi aprovada no dia 13 de Dezembro de 2016 e agora limita os gastos públicos com saúde, educação e outras áreas pelos próximos 20 anos.

Para alguns a greve foi em vão, no ambiente Universitário, diversos professores e alunos se mostraram contra o movimento e continuaram suas atividades. No que confere aos estudantes secundaristas e seus professores, muitos foram ameaçados pelos pais de alunos que não aderiram ao movimento e, até mesmo, pela Justiça Nacional.

Contudo, a importância da greve deve ser reconhecida, principalmente pelo fato de que o povo se uniu para lutar por um direito comum a todos. Mesmo que não tenhamos conseguido impedir a aprovação da "PEC da morte" lutamos incessantemente.

A paralisação da UFU durou mais de 50 dias, com início em 24 de outubro de 2016 e termino em 15 de dezembro de 2017. Após reunião do Conselho Universitário da UFU (Consun) o calendário de reposição das aulas foi estabelecido e a continuação do segundo semestre de 2016 ocorre entre os dias 30 de janeiro de 2017 a 13 de março de 2017.

\section{Considerações finais}

Ambas as medidas adotas pelo Governo são uma afronta a educação a nível nacional e, buscam a todo custo desmontar um direito a população, sendo esse, a educação emancipatória e que prepara os alunos para um futuro onde esses serão capazes de lutar pela garantia de seus direitos.

As ocupações nas escolas realizada pelos secundaristas ocorreu simultaneamente com a relação do Estágio Supervisionado II foi essencial para que conseguíssemos compreender que estamos diante de alunos que já não aceitam mais atos vindo do Governo que não os priorizem, estamos diante de alunos com força de vontade e luta expressamente forte.

Mesmo que as ocupações não tenham conseguido evitar a "Reforma do Ensino Médio", elas serviram para mostrar que nossos alunos estão a cada dia mais unidos e 
Nathalia Ohana Ferreira Santos

inteirados acerca dos seus direitos. A escola está viva e, através da força de seus alunos, será capaz de transformar a realidade das nossas escolas.

\section{Notas}

\footnotetext{
1Impeachment é uma palavra de origem inglesa que significa "impedimento" ou "impugnação", utilizada como um modelo de processo instaurado contra altas autoridades governamentais acusadas de infringir os seus deveres funcionais. Dizer que ocorreu impeachment ao Presidente da República, significa que este não poderá continuar exercendo as suas funções políticas.
}

\section{Referências}

RBA, Redação. EDUCAÇÃO PEC DA MALDADE Ocupações contra PEC 241 chegam a 1.108 escolas e 82 universidades. 2016. Disponível em:

$<$ http://www.redebrasilatual.com.br/educacao/2016/10/82-universidades-e-mais-de-milescolas-estao-ocupadas-contra-a-pec-241-871.html>. Acesso em: 28 fev. 2016.

SILVA, Anna Lúcia. UFU inicia greve em todos os campi e Eseba; PEC 241 está entre motivos. 2016. Disponível em: <http://g1.globo.com/minas-gerais/triangulomineiro/noticia/2016/10/ufu-inicia-greve-em-todos-os-campi-pec-241-esta-entremotivos.html>. Acesso em: 28 fev. 2017.

VILELA, Lilian. Greve na UFU termina após mais de 50 dias de paralisação. 2016. Disponível em: <http://g1.globo.com/minas-gerais/triangulomineiro/noticia/2016/12/greve-na-ufu-termina-apos-mais-de-50-dias-deparalisacao.html>. Acesso em: 28 fev. 2016. 